Revista de la red interuniversitaria de estudios sobre las literaturas rioplatenses contemporáneas en Francia

$8 \mid 2013$

Argentina y Uruguay: lecturas del país vecino en la literatura rioplatense contemporánea (siglos XX y XXI)

\title{
La disolución de las fronteras. Notas para pensar la "otra orilla" en la obra de Marosa di Giorgio
}

Adriana Gabriela Canseco

\section{OpenEdition}

Edición electrónica

URL: http://journals.openedition.org/lirico/934

DOI: $10.4000 /$ lirico.934

ISSN: 2262-8339

Editor

Réseau interuniversitaire d'étude des littératures contemporaines du Río de la Plata

Referencia electrónica

Adriana Gabriela Canseco, «La disolución de las fronteras. Notas para pensar la "otra orilla" en la obra de Marosa di Giorgio », Cuadernos LIRICO [En línea], 8 | 2013, Puesto en línea el 01 enero 2013

consultado el 20 abril 2019. URL : http://journals.openedition.org/lirico/934 ; DOI : 10.4000/lirico.934

Este documento fue generado automáticamente el 20 abril 2019.

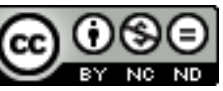

Cuadernos LIRICO está distribuido bajo una Licencia Creative Commons Atribución-NoComercialSinDerivar 4.0 Internacional. 


\title{
La disolución de las fronteras. Notas para pensar la "otra orilla" en la obra de Marosa di Giorgio
}

\author{
Adriana Gabriela Canseco
}

\section{En torno al gentilicio}

1 Que los cruces entre las literaturas argentina y uruguaya son de larga data es una verdad más que evidente. Las fronteras entre ambas zonas son tan frágiles, tan móviles que no muy a menudo nos preguntamos sobre sus límites, sus verdaderas interacciones. Es el lado argentino el que quizás más ha sabido nutrirse de la savia de la singularidad uruguaya, en un movimiento motivado tal vez por la simple inercia cultural y económica que ejerce la Argentina como territorio mayor. Resulta interesante hacer esta lectura de la diferencia cuando son generalmente los rasgos comunes los que unifican a menudo a las dos literaturas bajo la denominación de «rioplatense». No resulta sencillo en este punto discernir las singularidades que determinan aquello que podríamos denominar « literaturas nacionales ». Más allá de las fronteras geográficas, las influencias compartidas, la solidaridad histórica, el fluido tráfico de la lengua, acercan mucho más que lo que distancian a una orilla de la otra; será porque ambas literaturas están a un salto del charco de la otra: apenas un salto físico, pero también a un salto de su sensibilidad y de su imaginario.

2 Ha sido el argentino Sergio Chejfec quien se ha preguntado últimamente sobre los vínculos que unen a ambas literaturas, y que el autor identifica como constructos imaginarios sociales y culturales de larga data, sobre los que se asientan en una mezcla de admiración y nostalgia por un imposible o un posible irrealizado de lo propio, una potencialidad esquiva. Para Chejfec « el Uruguay es el locus metafórico por excelencia de la literatura argentina $»^{1}$, en el sentido en que más allá de la mitificación romántica, existe ciertamente una suerte de « fantasma [que] acompaña al paisaje argentino » que no es sino un reverso de lo propio, parcial pero amable, que conserva siempre la 
potencialidad del subjuntivo : «el Uruguay fue siempre la comarca ideal para señalar marcadamente lo distinto, lo que es parecido y por ello no puede ser igual, a lo sumo un poco equivalente $»^{2}$.

3 Si el Uruguay existe en la literatura argentina, existe para Chejfec, como promesa de algunas libertades, de cierto alivio de la carga histórica y como alternativa a los fracasos histórico-políticos inexcusablemente argentinos ${ }^{3}$. Él mismo señala que esta alusión a la tierra oriental puede equivaler de alguna manera a una añoranza infantil o familiar " decisiva en la calidad de la experiencia ${ }^{4}$. Si es que el país vecino, conserva el carácter del «sueño preservado de una Argentina imposible» es en gran medida a través de los lazos literarios que han preservado este imaginario desde el siglo XIX.

Bastan algunos ejemplos para ilustrar cómo la literatura uruguaya termina tarde o temprano siendo satelizada por la argentina, o mejor quizás, absorbida por los devenires de su historia literaria. Prueba de ello es que no existe panorama de la literatura argentina que no siga de cerca las implicancias y relaciones de una sobre la otra. Para Chejfec es indiscutible la influencia de los más populares, en la gestación de esta suerte de «utopía oriental », como en el caso de Juan Carlos Onetti. También están Galeano y Benedetti, cada uno ganando lectores en ambas orillas y abriéndose a esa indistinción dichosa que permite compartir la literatura cuando la identificación vacila entre el reconocimiento pleno y un vago extrañamiento que la hace permanecer apenas distante. Mención aparte merecen autores como Felisberto Hernández, Mario Levrero o Armonía Somers cuyas obras singulares irrumpen en el panorama de la literatura argentina en diversas circunstancias, permaneciendo fuera de la predicción normativizada de alguna clase de límite literario-geográfico (si es que es posible llamarlo así), en el que nunca se hace evidente un conflicto de fronteras. Un ejemplo ineludible de la literatura uruguaya que confundió hasta la indistinción las fronteras geopolíticas de la literatura, si es que las tiene, es el caso de Horacio Quiroga, ese hijo de la selva y de la aventura fatídica.

5 Aquí me detengo brevemente, y es que Horacio Quiroga era natural del Salto, una pequeña ciudad lindera con la localidad argentina de Concordia, separadas apenas por las aguas del Uruguay, donde también nació y creció la poeta que nos ocupa, Marosa di Giorgio. No se trata, sin embargo, de buscar coincidencias en hechos meramente anecdóticos, sino de pensar en qué medida la inicial distancia con la capital, Montevideo, la exigua distancia de un curso fluvial que separa una orilla de «la otra » durante la experiencia de una infancia salvaje, pueden haber influido en un olvido casi completo de fronteras tangibles entre literaturas. No es una novedad señalar que la obra de Quiroga es catalogada a menudo entre los estudios de literatura argentina; y es que este autor desarrolló plenamente su actividad literaria en la Argentina, seducido primero por el brillante panorama cultural del Buenos Aires de principio de siglo XX y más tarde por el vértigo indomesticable de la selva misionera. Como fuere, la literatura de Quiroga está marcada por el paisaje agreste y fluvial que eligió para sí mismo, como la de di Giorgio está atravesada por una experiencia rememorativa de la naturaleza que nunca deja de ser perturbadoramente seductora. La obra de di Giorgio nació y se desarrolló al margen de toda geografía probable. Si bien el Salto natal puede aparecer a veces como un vago motivo poético, no hay nada en su poesía o en su obra narrativa que se atenga a la referencia, a la reificación de un origen terrestre : la tierra natal deviene un paisaje mítico y para entrar de lleno en ese universo maravilloso es preciso aceptar de antemano esta premisa. 


\section{Marosa di Giorgio y la Argentina}

6 No estamos, como en el caso de Quiroga, ante una escritora que haya elegido vivir en la Argentina o que determinadas circunstancias la hayan obligado a tomar esa decisión. Marosa abandonó su ciudad natal recién en 1978 y luego se trasladó a Montevideo donde vivió hasta su muerte, en 2004. Nada en ese parco dato biográfico deja entrever el vínculo temprano e intensamente vivo que la unió con la Argentina.

7 Ya en 1955, Marosa, apenas conocida en su ciudad por la publicación de algunos poemas en la prensa local, publicó su segundo libro, Humo, en la ciudad de Santa Fe, a donde había ido a pasar una temporada con unos parientes instalados definitivamente del lado argentino. Dentro de su biografía puede ser más bien anecdótico el dato de esta sencilla edición de autor, sin embargo es ya un índice del magnetismo que la cercanía geográfica ejerce en los destinos literarios de muchos autores de «fronteras». De alguna forma empezaban ya a tejerse los lazos que más tarde arraigarían firmemente en el panorama de la poesía argentina actual.

8 Revisar la historia de sus publicaciones dentro y fuera de Uruguay puede ayudarnos a conjeturar las vías de la circulación que siguió esta voz poética en el trascurso de casi cinco décadas de producción ininterrumpida. Si bien no han sido la crítica ni la edición argentina las primeras descubridoras y difusoras del fenómeno marosiano, es notable en qué medida su injerencia ha incrementado la circulación de esta obra en todo el continente a partir de los años 90 .

9 El primer libro de di Giorgio, Poemas, apareció en Salto en 1953 en una humilde edición de autor, apenas un cuadernillo de dieciséis páginas. Al año siguiente, esta misma colección de poemas apareció junto con otra en un libro titulado Visiones y poemas, en Venezuela ${ }^{5}$, al igual que más adelante su cuarto libro, Druida, en 1959 y Magnolia, en $1965^{6}$. En este último, Marosa se presentaba como salteña y uruguaya pero jugando siempre en el umbral del paisaje fabuloso de la infancia, perpetuamente transfigurado por la palabra poética, en un no-lugar7. Es también en 1965, cuando recién su quinto libro, Historial de las Violetas, es publicado por primera vez en Montevideo en la colección Aquí Poesía.

10 Es a principios de los 70 cuando la obra de Marosa adquiere verdadero relieve con la publicación de su poesía reunida bajo el título de Los papeles salvajes. Las doscientas páginas de esta primera edición de Arca (Montevideo, 1971) ${ }^{8}$ tienen el valor de ser, además, el reconocimiento a una obra que ya había atestiguado, sobradamente hasta entonces, su solidez y originalidad. En aquellos años, la poesía de Marosa ya había sido recogida en varias antologías poéticas entre las que vale mencionar : Cien años de raros (1966) de Ángel Rama y Treinta años de poesía uruguaya (1967) de Alejandro Paternain, a las que después se sumarían otras como Antología crítica de la poesía uruguaya 1985-1990 (1990) de Roberto Apratto, Transplatinos (1991) y Medusario. Muestra de la poesía latinoamericana (1996) de Roberto Echavarren, Escritoras de América del Sur (1995) de Verónica Zondek.

11 García Helder señala en la nota biográfica que acompaña la edición definitiva de Los papeles salvajes, que «si en las décadas de 1960 y 1970 Marosa di Giorgio recibió sólo, aunque varios, reconocimientos y apoyos oficiales o institucionales, en las siguientes éstos se alternaron con los internacionales $»^{9}$. Efectivamente, entre las décadas de 1980 y 1990 fue el momento de un estallido general de la atención sobre su obra y sobre ella misma. A principios de los noventa Marosa estrenó sus recitales poéticos en Buenos Aires, 
en el Centro Cultural Ricardo Rojas, espectáculo de recitaciones con acompañamiento musical que había comenzado a presentar en Montevideo, cuando se mudó a esa ciudad a comienzos de los ochenta. Según Helder, Nicolás Olivari ya había escrito sobre su obra en varias revistas de Buenos Aires durante los setenta, como lo habían hecho también Ángel Rama y Cristina Peri Rosi en el semanario uruguayo Marcha. Este dato señala que la voz de di Giorgio era ya reconocida y citada por estudiosos y poetas a pesar de la limitada circulación que pudo haber tenido aquella primera edición de Arca.

La historia de sus ediciones se continúa con la aparición de sucesivos libros en la década de los ochenta que generó material suficiente para un segundo tomo de Los papeles salvajes. Así, en 1989 apareció una segunda edición del primer tomo de Los papeles salvajes de Arca que incluía un nuevo libro, Clavel y tenebrario (Arca, 1979). El segundo tomo, aparecido en 1991, incluía : La liebre de marzo (Cal y Canto, 1981), Mesa de esmeralda (Arca, 1985), La falena (Arca, 1987), y el hasta entonces inédito, Membrillo de Lusana (1991).

13 En 1995, Diario de Poesía le dedica un dossier a la obra de Marosa di Giorgio, dirigido por Osvaldo Aguirre y Daniel García Helder. Este dato resulta fundamental puesto que no sólo es una instancia consagratoria para la obra de Marosa di Giorgio en Argentina sino que en esta circunstancia se reúnen por primera vez una serie de voces críticas dispersas que venían ya pensando en torno a esta extraña de las letras rioplatenses. Este gesto inscribe además a su obra en un lugar particular del panorama de la poesía latinoamericana que va trazando Diario de poesía en esos años. Este dossier incluía ensayos críticos, una extensa entrevista, textos de análisis que se sumaban al coro fantástico de la alucinación marosiana, reseñas, datos biográficos, fragmentos del libro, inédito hasta entonces, Diamelas a mi madre y uno de sus relatos eróticos perteneciente a Misales (Cal y Canto, 1993, reeditado en Francia, Colombia, Chile y Argentina). Como fuere, esta relación cada vez más consolidada con la poesía argentina (se suceden numerosas entrevistas, encuentros, recitales poéticos, festivales de poesía, etc.) da sus frutos en forma de nuevas e importantes ediciones de su obra.

14 Fue justamente su relación con García Helder la que propició inicialmente la alianza que conocemos hoy entre la obra de di Giorgio y la editorial Adriana Hidalgo ${ }^{10}$. Si nos adentramos en la experiencia vital de di Giorgio frente a las repercusiones de su poesía, veremos que el reconocimiento de la crítica y el impulso internacional de su obra fueron un notable paso personal y económico en su carrera. Como señala uno de sus biógrafos y amigo, el poeta uruguayo Leonardo Garet :

El mundo editorial y la crítica de Montevideo acogieron a Marosa con unánime aprobación, aunque las editoriales no acompañarían el reconocimiento con una retribución económica, y la dádiva de algunos ejemplares fue todo lo que obtuvo. Lo comentábamos siempre. En 1997, cuando la edita una editorial extranjera, por primera vez firma un contrato y recibe un pago por adelantado. Desde Los papeles salvajes, Marosa era muy leída en nuestro país, por lo que se puede probar, una vez más, que el profesionalismo de un escritor de ficción que respalde sus ventas exclusivamente en la calidad literaria, es nada más que una utopía en Uruguay ${ }^{11}$.

En 2000 apareció una edición argentina de Los papeles salvajes en dos tomos con un prólogo de Silvio Mattoni ${ }^{12}$ que renovaba el impulso crítico en torno a la obra iniciado con Diario de Poesía cinco años antes. Existe asimismo una segunda edición de Adriana Hidalgo, de Los papeles salvajes (2008), preparada por Daniel García Helder, que agrega al contenido casi idéntico de la anterior una nota bibliográfica y datos relevantes referidos a las primeras publicaciones, al tiempo que se salvan erratas históricas y se incorporan algunas páginas inéditas. 
La otra gran parte de la obra marosiana, y quizás la que goza de mayor popularidad de ventas, está compuesta por una serie de libros de relatos eróticos: Misales (Cal y Canto, Montevideo, 1993), Camino de las pedrerías (Planeta, Buenos Aires, 1997), Rosa Mística (Buenos Aires, Interzona, 2003) ${ }^{13}$. Todos estos libros fueron publicados también por editoriales argentinas como Interzona y El cuenco de plata y reunidos posteriormente en otra edición de El cuenco de plata (Buenos Aires, 2008) bajo el título general de El Gran Ratón Dorado. El Gran Ratón de lilas (Relatos eróticos completos).

17 Su obra publicada se completa con Reina Amelia (Adriana Hidalgo, 1997), un relato extenso que fue separado del conjunto y publicado como novela, y su último libro, La flor de lis (El cuenco de plata, 2004), que se publicó poco antes de su muerte y en la que la autora retoma el breve poema en prosa característico de Los papeles salvajes. Esta edición está además acompañada por una grabación en $\mathrm{CD}$, Diamelas, que recoge veintiséis de los poemas que formaban parte de sus recitales poéticos.

\section{Marosa en el panorama poético latinoamericano}

Si, como señalaba Sergio Chejfec, el Uruguay ha sido siempre un espejo benévolo para la cultura argentina en general y un « locus metafórico » de su literatura, habrá que rastrear qué clase de influjo ejerció la obra marosiana en la poesía argentina de las últimas décadas, más allá de estas hipótesis que consideran una presencia poco más que comprobable de « la otra orilla».

Como señalamos, el exuberante universo marosiano prolifera fuera de cualquier previsión generacional, programática o genérica, lo cual favorece en gran medida el desarrollo de un discurso crítico que apuesta a la confrontación de hipótesis, a la mirada divergente ${ }^{14}$. Si hay algún acuerdo en torno a su escritura, éste está referido a cierta inaccesibilidad del íntimo universo marosiano, que procede no tanto por pudor o deliberado ocultamiento sino más precisamente por exceso, por una arbitraria y desenfrenada proliferación. Daniel Helder señalaba en el dossier de Diario de poesía :

La obra de Marosa di Giorgio [...] no presenta evolución ni fisuras : parece o bien haber sido escrita de una vez o bien estar en permanente proceso de escritura. Desde su primer libro Poemas (1954) hasta [sus libros] más recientes, lo que se percibe no es una evolución sino más bien una expansión de lo mismo, la metamorfosis múltiple y continuada de una naturaleza extravagante donde lo humano, lo animal, lo vegetal y lo mineral, como en los cuadros de Archimboldo, no están separados sino mezclados en cada $\operatorname{ser}^{15}$.

Es evidente que di Giorgio no buscaba la notoriedad y ni la mera polémica en torno a su estilo, en apariencia, abiertamente provocativo, sino más bien una solidaridad ética en el reconocimiento íntimo que no se agotaría en la evocación sentimental del terruño y de la infancia perdia, al estilo de los neorrománticos. Más bien todo lo contrario, su apasionado lenguaje poético busca suspender las categorías de espacio y tiempo para sumergirnos en un no-tiempo y en un no-lugar. Ácrona y atópica, la poesía de di Giorgio apela a los sentidos antes que a la memoria, a la acumulación y a la saturación verbal antes que a una remembranza lírica entendida como el languidecimiento decadente de una belleza perdida. La singularidad que la apartó siempre del alcance masivo, puede ser entendida también como una postura estética que elige uno a uno a sus lectores hablando una lengua común, antigua : la primera lengua, la de la mirada infantil que se abría azorada ante la sorpresa del mundo. Dice en una entrevista : 
Un autor no leído no tiene sentido. No voy a buscar nunca la popularidad masiva, ni me voy a desvivir por eso, pero quiero que ese barco, que esa nave que eché a andar, marche, camine. $\mathrm{Y}$ pasa una cosa muy rara también. Hay gente de poco cultivo a la que le interesa mi literatura. Será porque lo cotidiano está presente, la gente se encuentra con lo que vio, con lo que ve todos los días ${ }^{16}$.

Pero la imagen tutelar de Marosa di Giorgio en la poesía latinoamericana trasciende esa voluntad de hacer de su universo privado un espacio literariamente habitable. En gran medida es la crítica la que ha puesto la obra de di Giorgio en cuestión para interrogarla en materia de filiaciones posibles, de afinidades estéticas.

\section{Lecturas de una y otra orilla}

Los primeros textos críticos uruguayos, o al menos los que más han circulado fuera del circulo amical que rodeó a la poeta y a sus obras, se deben en gran parte a Roberto Echavarren, quien ya a principio de los ochenta incluía la lectura de la poesía de di Giorgio en su cátedra de Literatura Latinoamericana en la Universidad de Nueva York ${ }^{17}$. Wilfredo Penco y Luis Bravo también ocuparon un lugar destacado en la difusión y lectura crítica de la obra de di Giorgio. Aunque ellos mismos formaran parte de sus más cercanos amigos, pudieron ofrecer una mirada más aguda sobre la potencia de la singularidad marosiana. Es Roberto Echavarren quien mejor actualiza su posición en el panorama histórico-literario uruguayo :

Di Giorgio tiene simpatía por la escritura de Delmira Agustini, Concepción Silva Belinzon y Amanda Berenguer. Pero salvo reminiscencias ocasionales, la poesía de Di Giorgio presenta un cariz inconfundible. Y es notoria la cohesión de su trabajo, la continuidad del tono, de los procedimientos y del material anecdótico. La obra de Di Giorgio no tiene nada que ver con los programas y los proyectos que se consideraban validos en el Uruguay de los años sesenta, dominados por una poesía coloquial y «comprometida » que ofrece hoy, como entonces para los lectores exigentes, las marcas patéticas de su insuficiencia [...] En Di Giorgio, en cambio, aflora una conciencia muy aguda del artificio, de la extravagancia, la burla y los disfraces. Lo familiar, en su obra, aparece como no familiar [...] es una cuestión de sujeto y escritura: entabla el estatuto de la ficción a partir de un presente no ausente, no anquilosado, no obliterado de antemano por el cliché ${ }^{18}$.

Queda claro que la crítica uruguaya, al menos por el lado de Echavarren, reconoce algunas filiaciones con la poesía uruguaya anterior aunque para ello tenga que remontarse al modernismo de Delmira Agustini, Julio Herrera y Reissig o a las figuras todavía más difusas del conde de Lautréamont y Jules Laforgue, como una manera de enmarcar la producción de una obra, a primera vista, inclasificable. Echavarren desarrolla una red de voces posibles de la siguiente forma :

Uruguay no tuvo ni un Lezama Lima, ni un Borges, ni un Octavio Paz, ni un Vallejo, ni un Neruda, es decir, no tuvo un poeta fuerte de vanguardia. Sí tuvo, en la ficción, dos figuras cruciales : Juan Carlos Onetti y Felisberto Hernández. Pero el momento fuerte de la poesía uruguaya escrita en castellano fue el modernismo, con Delmira Agustini y el Julio Herrera y Reissig de La torre de las esfinges. La poesía uruguaya escrita en francés ya había tenido su momento culminante en la segunda mitad del siglo diecinueve. [...] Isidore Ducasse (Lautreamont) y Jules Laforgue, gracias al hecho de escribir en francés y de pasar una parte de sus cortas vidas en Europa, proyectaron, como fundadores de la modernidad, sus trayectorias no sólo sobre el modernismo hispanoamericano que intentó digerirlos, sino sobre el simbolismo y el surrealismo franceses [...] De Lautreamont, Di Giorgio hereda los rasgos animales o inhumanos, a ratos feroces, las transformaciones vertiginosas del yo lírico y de 
cualquier otra presencia o interlocutor [...]. De Jules Laforgue, Di Giorgio hereda la pantalla complementaria de la luna, la superficie intocable sobre la que se reflejan los objetos platónicos de un apetito de insatisfacción ${ }^{19}$.

Echavarren, y en este caso como contracara del germen neobarroco, el resurgimiento de una línea coloquialista-comprometida (resabio de la poesía revolucionaria de los 60-70) que se aviva con la vuelta de la democracia y que tiene a Juan Gelman como abanderado. Contra todo pronóstico, es, según Prieto, Ricardo Zelarrayán quien encabeza, por así decir, una nueva línea de sensibilidad poética, más afín a Lamborghini. La política vinculada al neobarroquismo, claro está, no desapareció sino que ocupó otros espacios, se diversificó en voces menos miméticas y muchísimo más complejas que la de los coloquialistas de los 60-70.

nos interesa, sin embargo, son las proyecciones y vinculaciones del neobarroco argentino con el resto del continente y es que, como señala Prieto, después del Modernismo la poesía argentina se abstuvo del contacto asiduo y del intercambio con el 
resto de las literaturas. Si las vanguardias habían cerrado las fronteras literarias a lo extranjero latinoamericano, el neobarroco volvió a poner en vigencia el diálogo interrumpido. Es en este punto en que la obra de di Giorgio atisba un horizonte de diálogo posible con la poesía argentina actual ${ }^{26}$.

Pero es la efervescencia de la provocación neobarroca la que señala Prieto como uno de los alicientes de su reactivación permanente y su vigencia. Sus discutidos y discutibles límites y características generaron una respuesta desde Diario de poesía, firmada por Daniel García Helder, bajo el título de $"$ El neobarroco en la Argentina $»^{27}$ que no solo impugna la clasificación neobarroca sino que divide las aguas en favor de lo que más adelante se conoció como "ojbetivismo». Frente a esta polémica, y en la "orilla opuesta » del interés de identificarse con una determinada estética, la obra de di Giorgio continuaba gestándose, un tanto indiferente a estas polémicas. Más allá de las apropiaciones y renuncias que uno y otro colectivo hicieran de la obra de los poetas más o menos consagrados, el valor de estas arduas discusiones radica en que en ese mismo movimiento se propiciaba la difusión y publicación de poetas apenas conocidos para los más jóvenes, como de hecho sucedió con la publicación del dossier dedicado a di Giorgio en 1995 y de muchos otros poetas en aquellos años. Es insoslayable, llegado este punto, reconocer el meritorio trabajo que durante ya más de 25 años ha realizado Diario de Poesía en la difusión de nuevas voces, en homenajes rendidos y compendios sumatorios que mantienen una mirada vigilante sobre el pasado reciente de la poesía argentina con miras a garantizar, por una u otra vía, su futuro.

Si echamos una mirada al panorama joven de la poesía argentina, si dejamos de pensar la orilla opuesta de la literatura como « otra », veremos que la obra de di Giorgio ha dado y sigue dando, quizás desiguales, frutos argentinos. Pero poco importa que el vástago se evidencie cercano a la especie que le ha dado forma, porque como sabemos, las diferencias de género o naturaleza no generan controversia en la esfera del pensamiento marosiano. Para Marina Mariasch el panorama de fines del siglo XX y principios del XXI de la poesía argentina atestigua la promisoria influencia de voces plurales entre las que la obra de di Giorgio ocupa un lugar destacado. Cabe señalar que en este breve pantallazo todavía se agitan aquellos vientos neobarrocos que tanto se afanaron en moderar las voces críticas desde Diario de Poesía a principio de los noventa :

La presencia de Marosa di Giorgio en los textos actuales también fulgura. Las referencias más evidentes surgen frente a Gabriela Bejerman y Fernanda Laguna, ambas poetas nacidas a comienzos de los '70 y que alguna vez publicaron con seudónimos de flores (Lirio, Dalia). En la primera, la exuberancia y la yuxtaposición, la sensualidad de un mundo donde todo seduce o da miedo, la cualidad barroca de algunas líneas. En Laguna, la percepción de un mundo como recién inaugurado, donde las tareas domésticas y las « cosas de la casa » (un budín recién horneado que se eleva) sorprenden como trucos de magia. Pero hay otras conexiones más sutiles. Por ejemplo, la que liga a Di Giorgio con el poeta Martín Rodríguez (1978) que, como ella, tiene en el centro de su poética al huevo, fértil, germen. Para Marosa, un huevo « es la pequeña gema, o lo que fuere, de donde se produjo el Big Bang, y otra cosa más recóndita, y cálida, como un capullo tibio, caliente. Algo ahí ; en la entraña, un inicio, un pío, un latido, una perla, un huevo, una... molestia diabólica y celeste ». Es probable, también, que la prosa de Di Giorgio haya sobrevolado la escritura de algo de la producción de Washington Cucurto. Y un libro precioso, Las bellezas del lobo, de Julia Sarachu (1976), guarda alguna relación con la uruguaya ${ }^{28}$. 


\section{Conclusiones}

31 Lo que se respira en torno a la obra marosiana es justamente una intensa libertad que se acompaña con una necesidad casi física de liberar al lenguaje de sus ataduras lógicas, del embozo de la metáfora, del juego de palabras cuando engendra algún sentido moral. Todo lirismo convencional sucumbe ante esta concepción de un lenguaje literal ; literalidad que sugiere que ese lenguaje ha sido liberado a sus más urgentes instintos; es decir, liberado a la referencialidad inmediata de, por ejemplo, la poesía del haiku (en la precisión y el verismo de su lenguaje) pero al servicio de las fantasías más desembozadas de aquello que había quedado silenciado en una infancia que carecía de nombres.

En la obra de Marosa di Giorgio, no hay, como vimos, el menor énfasis nacionalista, ni siquiera regionalista. ¿Cómo debemos leer entonces su poesía? ¿Es posible acaso, o al menos útil, ubicarla en alguna dicotomía que la fuerce, que la obligue a poner en juego su integridad ontológica, su ética pluralista? Si las pujas y polémicas del Neobarroco pusieron algo de esto en juego, la poesía marosiana ha demostrado que puede salir indemne, en su juventud y vigencia, porque hay en su fondo una unidad que reniega de todas las clasificaciones. Los papeles salvajes han sido concebidos en una intimidad tan auténtica que de tan honda y peculiar solo puede volcarse al más amplio universalismo.

Marosa cruzó, innumerables veces, de una orilla a la otra ; disfrutó en ese pasaje de las viejas y las nuevas amistades, del prestigio y del mimo que se prodigó a su persona y a su obra, del afecto de su público y de sus lectores. Nosotros también hemos intentado, en este trabajo, cruzar de una orilla a la otra de las miradas y las voces que construyeron y construyen el imaginario crítico sobre una obra que consideramos, en el más amplio sentido de la palabra, extraordinaria.

\section{NOTAS}

1. S. Chejfec. «La parte por el todo. Alegato oriental», 2002, consultable en http:// parabolaanterior.wordpress.com/2009/01/01/la-parte-por-el-todo/, 20/09/2012.

2. Idem.

3. Sergio Chejfec señala en este mismo artículo: «El Uruguay esconde también un núcleo de existencia pedestre y de sabiduría social, frente al que la literatura, o sea la creación, no permanece impávida. Cuando se trata del Uruguay las narraciones argentinas adquieren otro aire y asumen una escala mayor, los hechos se desarrollan con más profundidad, prometen un final dilatado y, por sobre todo, los personajes logran un perfil subjetivo más complejo, acorde con una tipología no vigilada por la historia política o el enfrentamiento social. La lista de autores argentinos que han tenido la debilidad de aludir al Uruguay o los uruguayos es larga, antigua y actual. Debajo de los textos se intuye la Banda Oriental como un paraíso sociológico y un remanso cultural, el seductor experimento imaginario hacia una Argentina sin populismos. Quizá esta sea la incógnita uruguaya, un blasón no-peronista que cautiva con su brillo discreto, ajeno a nuestra frustración histórica », Idem.

4. Idem.

Cuadernos LIRICO, 8 | 2013 
5. «La misma serie de poemas fue incluida junto a otra más larga, en Visiones y poemas, libro de 62 páginas publicado en el número 135 de Lírica Hispana, Caracas, 1954. El volumen incluía sendas presentaciones de las directoras de la colección, Conie Lobell y Jean Aristeguieta [...] El 1971, cuando la editorial Arca, de Montevideo, reunió sus siete primeros libros bajo el título unitario de Los papeles salvajes, di Giorgio decidió excluir las serie Visiones, decisión que se sigue respetando ». Marosa di Giorgio. Los papeles salvajes. Edición íntegra. Cuidado de la edición, notas y síntesis biográfica a cargo de Daniel García Helder, Buenos Aires, Adriana Hidalgo, 2008, p. 16.

6. Ibid., p. 60. «Druida, colección Lírica Hispánica número 196, Caracas, junio de 1959 », « [ Magnolia] fue editado en el número 266 de la colección Lírica Hispana de Caracas, junio 1965 ».

7. Ibid., p. 110. La edición venezolana de Magnolia incluía también unos versos autobiográficos en los que Marosa se presentaba a los lectores : « Nací y vivo en Salto Uruguay,/ una ciudad que queda cerca del agua y de la luna./ Mi infancia está en los campos,/ los árboles, los demonios,/ los perros, el rocío ;/ queda en medio del arvejal,/ y dentro de la casa ;/ a veces, venía a visitarme el arco iris,/ serio como un hombre,/ las larguísimas alas tocando el cielo./ Mi infancia es la luna,/ patente como una rosa,/ y el grito de los muertos,/ Mis libros de poemas se llaman/ Poemas, Humo,/ Druida, Historial de las violetas, Magnolia./ Lo demás, es todavía, hoy y mañana,/ y no me importa ».

8. La primera edición de Arca de Los papeles salvajes (1971) incluía los ya citados : Poemas, Humo, Druida, Historial de las violetas, Magnolia, y se sumaban dos títulos inéditos hasta entonces, La guerra y de los huertos y Está en llamas el jardín natal.

9. D. García Helder. « Síntesis biográfica de Marosa di Giorgio » en Marosa di Giorgio. Los papeles salvajes, op.cit., p. 664.

10. Al respecto resulta interesante un testimonio aportado por Marosa misma respecto a la edición argentina de sus libros: «Una de estas cálidas mañanas recibí un llamado de Daniel [García Helder] comunicándome que una dama argentina, una de las dueñas de las poderosas librerías Ateneo, iniciaba esta línea editorial y que mi suma poética Papeles salvajes había sido propuesta y aceptada para esas ediciones. Se iniciarán esmeradamente y con miras a una muy amplia difusión, dentro y fuera de Argentina », citado por Melisa Machado, « A escribir he venido al mundo » en El País Cultural, n 512, Montevideo, 18 de junio de 1999.

11. L. Garet, El milagro incesante. Vida y obra de Marosa di Giorgio, Montevideo, Aldebarán, 2006, p. 59. El contrato al que Garet probablemente se refiere es el de la edición de Reina Amelia (Adriana Hidalgo 1997), el extenso e inclasificable relato que, por una decisión editorial, fue separado del conjunto de escritos que se clasificaron como "relatos eróticos » y publicado, independientemente, como novela.

12. S. Mattoni., "Allá donde alumbra la imagen », prólogo en Marosa di Giorgio. Los papeles salvajes I, Buenos Aires, Adriana Hidalgo, 2000.

13. Todos estos libros fueron reunidos bajo el título general de El Gran Ratón Dorado. El Gran Ratón de lilas (Relatos eróticos completos, Buenos Aires, El cuenco de plata, 2008).

14. A. Genovese, « El imaginario del poema. Marosa di Giorgio » en Leer poesía. Lo leve, lo grave, lo opaco, Buenos Aires, Fondo de Cultura Económica, 2011, p. 115-126. En su ensayo, Alicia Genovese sugiere caminos alternativos a los seguidos hasta el momento por la crítica marosiana, a la que no pocas veces le cuesta sustraerse a la fascinación de un lenguaje cíclico y que termina por empantanarse en la repetición y el aparente agotamiento. La propuesta de Genovese sugiere ahondar la mirada sobre sus estructuras, siendo más sensibles a una escucha del habla poética que teje ese universo, allí donde residiría su singularidad (incluso más que en la originalidad de sus motivos) y que es, en definitiva, un cuestionamiento ético sobre el lenguaje que interroga profundamente nuestra concepción de la literatura. No podemos dejar de mencionar que probablemente Genovese eluda el epíteto « argentina » del título de su libro, para referirse a la poesía, con el único propósito de incluir su lectura de la poesía Marosa di Giorgio en esta antología crítica ya que el resto de los poetas citados en ella son todos argentinos. Otra muestra 
más de la gravitación de la obra marosiana en el panorama de la crítica argentina de poesía y de las afinidades del pensamiento poético-crítico de ambas orillas, al menos en lo que se refiere a di Giorgio.

15. O. Aguirre y D. García Helder (eds.), « Dossier : Marosa di Giorgio », en Diario de poesía, n 34, Junio-Agosto, Buenos Aires, 1995.

16. R. Mérica, «Delicias en el jardín de las maravillas », reportaje en El Día, Montevideo, 26 de julio de 1981.

17. L. Garet, op.cit., p. 62.

18. R. Echavarren, "Marosa di Giorgio, última poeta del Uruguay » en Revista Iberoamericana, vol. LVIII, $n^{\circ}$ 160-161, julio/diciembre, 1992, p. 1103.

19. R. Echavarren, « Marosa di Giorgio, última poeta del Uruguay », op.cit., p. 1104.

20. S. Sarduy. El barroco y el neobarroco. Ensayos, Buenos Aires, El cuenco de plata, 2011. [Originalmente publicado en C. Fernández Moreno (coord.), América Latina en su literatura, México/París, Siglo XXI/Unesco, 1972].

21. A. Minelli (2003), «Las olvidadas del neobarroso : Alejandra Pizarnik y Marosa di Giorgio » en Revista La Aljaba, Segunda época, vol. VII, p. 195.

22. N. Perlongher, «Caribe transplatino» en Prosa plebeya. Ensayos 1980-1992, Buenos Aires, Colihue, 1997, p. 93-102.

23. Ibid, 102.

24. M. Prieto, « Neobarrocos, objetivistas, epifánicos y realistas : nuevos apuntes para la historia de la nueva poesía argentina » en S. Delgado y J. Premat (eds.), Movimiento y nominación. Notas sobre la poesía argentina contemporánea, Cahiers de LI.RI.CO, oㅡ 3, Université de Paris 8 - Université de Bretagne-Sud, Paris, 2007, p. 23-44.

25. M. Prieto, « Neobarrocos, objetivistas, epifánicos y realistas : nuevos apuntes para la historia de la nueva poesía argentina », op.cit, p. 24.

26. Prieto señala al respecto : «el chileno Enrique Lihn, en el libro de Kamenszain de 1983, el cubano Severo Sarduy, entusiasta prologuista de Ciudad del colibrí, una antología de Carrera publicada en España en 1982, la uruguaya Marosa di Giorgio, el brasileño Haroldo de Campos y, en todos, el cubano san José Lezama Lima. Eso, hacia atrás. Y hacia los costados, los uruguayos Roberto Echevarren, Eduardo Milán, Eduardo Espina, el brasileño Wilson Bueno, autor de Mar paraguayo, escrito en portuñol-guaraní, el chileno Diego Maquieira, el cubano José Kozer». Martín Prieto, « Neobarrocos, objetivistas, epifánicos y realistas : nuevos apuntes para la historia de la nueva poesía argentina », op.cit, p. 27.

27. D. García Helder, «El neobarroco en la Argentina » en Diario de Poesía, n 4, Buenos Aires/ Rosario/ Montevideo, otoño de 1987.

28. M. Mariasch, «El sexo de las flores » en Diario Perfil, Año III, no 293, Buenos Aires, 2008. p. 23.

\section{RESÚMENES}

La obra de Marosa di Giorgio (Salto, 1926- Montevideo, 2004) se hace en un territorio cuyas fronteras siempre fluctuantes en lo formal y lo temático, desde mediados de los 90 en la Argentina, propiciaron una visión de su poética que trasciende las delimitaciones de las literaturas nacionales. La historia de la recepción de la obra marosiana está hecha del cruce de voces críticas desde una y otra orilla. Este diálogo, que permanece ininterrumpido de ambas 
partes, pone en evidencia no sólo el mutuo interés en una voz poética de extrema singularidad sino que señala un proceso de mutua retroalimentación para acercarse críticamente a una obra singular. La inclasificable obra de di Giorgio permanece fuera de cualquier previsión generacional e incluso genérica, lo cual es en sí un aliciente para el desarrollo del discurso crítico. Si bien la obra de Marosa di Giorgio era ya conocida y difundida en Argentina por una pequeña minoría de intelectuales y artistas en la década del 70 y el 80, recibió un impulso definitivo con la aparición en 1995 de un dossier dedicado a la autora en Diario de Poesía preparado por Daniel García Helder y Osvaldo Aguirre. Este primer acercamiento a una obra prácticamente desconocida hasta entonces supuso el inicio de un fecundo intercambio de lecturas críticas y abrió paso a la edición argentina de todos sus libros, constituyéndose en un referente bibliográfico cuyo interés no deja de crecer. Referencias culturales y epocales mínimas forman parte del universo poético familiar-extrañado creado por di Giorgio, un universo que excede, en general, la etiqueta de las literaturas nacionales. La " otra orilla », aquella siempre extranjera pero cercana para la otra, supone una mirada doble que pone en cuestión el territorio común de esa lengua poética compartida y a la vez tiene el desafío de descubrir sus rasgos de singularidad propios.

L'œuvre de Marosa di Giorgio (Salto, 1926 - Montevideo, 2004) s'inscrit dans un territoire dont les frontières, toujours indécises tant d'un point de vue formel que thématique, ont suscité, dès les années 90 en Argentine une vision de sa poétique qui s'affranchit des délimitations des littératures nationales. L'histoire de la réception de l'œuvre marosianne constitue un réseau de voix critiques émanant des deux rives du Río de la Plata. Ce dialogue, ininterrompu entre les deux pays, met en évidence non seulement l'intérêt mutuel porté à une voix poétique très singulière, mais également un processus de rétro-alimentation mutuelle pour s'approprier, grâce à la critique, une œuvre originale. L'œuvre de di Giorgio demeure inclassable hors de toute caractéristique générationnelle ou générique, ce qui constitue ainsi un défi pour le discours critique. Bien que l'œuvre de Marosa di Giorgio soit déjà connue et diffusée en Argentine par une petite minorité d'intellectuels et d'artistes dans les décennies 1970 et 1980, elle a atteint sa réelle notoriété avec l'apparition en 1995, d'un dossier dédié à l'auteur dans Diario de Poesía préparé par Daniel Helder et Osvaldo Aguirre. La reconnaissance de cette œuvre, pratiquement ignorée autrefois, a supposé non seulement le début d'un échange fertile de lectures critiques, mais il a aussi ouvert la voie à la publication de tous ses livres dans les éditions argentines, devenant une référence bibliographique dont l'intérêt n'a pas cessé de croître.

Peu de références culturelles et temporelles font partie de cet univers poétique, familial et étonnant, qu'a créé di Giorgio. Cependant, cet univers dépasse l'étiquette des littératures nationales. L'autre rive demeure toujours étrangère mais proche pour chaque littérature et pour chaque tradition critique. Cela suppose un double regard qui met en question le territoire commun du langage poétique partagé entre deux cultures voisines et propose, en même temps, un défi pour découvrir ses propres traits de singularité.

Marosa di Giorgio's work is a territory whose borders, always fluctuating both on a formal and a thematic level, have generated since the 1990s in Argentina, a poetic vision that transcends the boundaries of national literatures. The history of the reception of di Giorgio's work usually entwines critical voices from both shores. This uninterrupted dialogue on both sides of the Rio de la Plata can be explained by the common interest for a poetic voice of extreme uniqueness; it also shows a process of mutual feedback, necessary for critically approaching a work without precedent in Latin American literature. Di Giorgio's unclassifiable work doesn't conform to generational or generic categories, and results itself an incentive for the development of a critical discourse. While the work of di Giorgio was well-known in Argentina by a small minority of intellectuals and artists in the decades of 1970 and 1980, the dossier dedicated to her work in 1995's Diario de Poesía (prepared by Osvaldo Aguirre and Daniel Garcia Helder) was a definite boost. This first approach to a so far practically unknown work entailed not only the beginning of 
a fruitful exchange of critical readings, but also resulted in the complete edition, in Argentina, of all of her books, a volume that has already become a bibliographical reference of growing interest.

Minimum cultural and epochal references are part of the familial-strange poetic world created by di Giorgio. This universe exceeds, in general, the label of national literatures. The "other shore ", that other shore which is always foreign yet so close, asks for a double look that calls into question the common ground of poetic language and, at the same time, challenges the quest for its own unique traits.

\section{ÍNDICE}

Palabras claves: Marosa di Giorgio, poesía, edición, recepción, Diario de Poesía

Keywords: Marosa di Giorgio, poetry, edition, reception, Diario de Poesía

Mots-clés: Marosa di Giorgio, édition, poésie, réception, Diario de Poesía

\section{AUTOR}

\section{ADRIANA GABRIELA CANSECO}

Universidad Nacional de Córdoba - CONICET 